\title{
A acupuntura no Brasil: uma concepção de desafios e lutas omitidos ou esquecidos pela história - Entrevista com dr. Evaldo Martins Leite
}

Acupuncture in Brazil: a conception of challenges and struggles omitted or forgotten by history - Interview with doctor Evaldo Martins Leite

Acupuntura en Brasil: una concepción de retos y luchas omitidos u olvidados por la historia - Entrevista con el dr. Evaldo Martins Leite

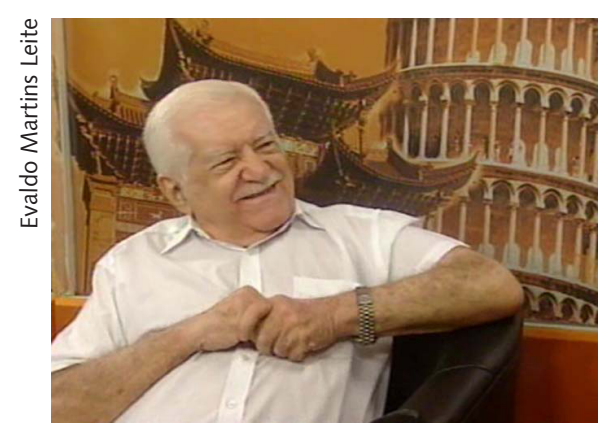

Sabrina Pereira Rocha ${ }^{(a)}$ Dante Marcello Claramonte Gallian ${ }^{(b)}$

Esta entrevista foi concedida pelo dr. Evaldo Martins Leite no dia 16 de julho de 2012, em seu consultório na Associação Brasileira de Acupuntura, em São Paulo. ELe é médico cardiologista e ex-professor da Faculdade de Medicina Santa Casa de Misericórdia de São Paulo. Acupunturista desde a década de 1950, é considerado pioneiro da acupuntura tradicional no Brasil e no exterior. É um dos fundadores e, atualmente, presidente da Associação Brasileira de Acupuntura ( $A B A)$. Os encontros foram realizados em seu consultório na $A B A$ e marcados pela sua simpatia, atenção e transparência. Sua devoção à acupuntura é fascinante. Foi com pesar que ouvi o dr. Evaldo relatar suas dificuldades e, com admiração, pela sua coragem para enfrentá-las. A história de vida do dr. Evaldo Martins Leite foi capaz de captar fatos esquecidos ou omitidos pela história. Ele traduz, de forma simples e transparente, suas experiências.

Como mencionado, a narrativa foi produzida segundo a metodologia da História Oral de Vida, tal como é proposta por Galliann ${ }^{1}$, Meihy ${ }^{2}$ e Meihy e Holanda $^{3}$. De acordo com Meihy ${ }^{2}$ (p. 17), a História Oral, "além de renovada pelo uso de aparelhos eletrônicos e com fundamentação moderna, é dinâmica e criativa, fato que torna discutível qualquer conceituação fechada".

Esta abordagem segue um rigoroso conjunto de procedimentos para a constituição das narrativas, que garantem a ética e a validade das mesmas como documentos a serem analisados2: (1) gravação das entrevistas; (2) confecção do documento escrito: transcrição, textualização, transcriação - texto recriado em sua plenitude, nesta fase sofrerá a interferência do autor, tudo obedecerá aos acertos combinados com o colaborador, que irá legitimar o texto no momento da conferência; (3) conferência e validação do documento escrito; (4) análise; (5) devolução do produto.

\footnotetext{
(a) Departamento de Medicina Preventiva, Universidade Federal de São Paulo (Unifesp). Rua Botucatu, 740, $4^{\circ}$ andar, Vila Clementino. São Paulo, SP, Brasil. 04023-062 sp.rocha1986@ uol.com.br

(b) Centro de História e Filosofia das Ciências da Saúde, Unifesp. São Paulo, SP, Brasil. dante.cehfi@epm.br
} 


\section{Breve introdução e contextualização}

Eu sou Evaldo Martins Leite, nasci no Rio Grande do Norte, numa cidadezinha portuária chamada Areia Branca, que apresenta um movimento de trabalho bem intenso, porque, além de ser uma cidade portuária, tem sal e petróleo. Eu fiz o meu primário em Areia Branca, depois, fui para uma cidade vizinha chamada Mossoró, onde fiz o ginásio. Posteriormente, com 15 anos, eu fui para Fortaleza, onde realizei, naquele tempo, o colegial, prestei o vestibular para medicina e fiz o curso de Medicina lá no Ceará...

Quando terminei o curso de Medicina, fui para Porto Alegre fazer minha pós-graduação, me especializei em Cardiologia e fiz meu doutorado. O meu chefe era orientador geral e primeiro Prêmio Nobel de Medicina da América Latina, o argentino Bernardo Alberto Houssay. E como eu fiz um doutorado muito prestigiado na época, fui convidado para vir trabalhar na Santa Casa de Misericórdia de São Paulo, onde trabalhei como professor durante muitos anos.

\section{Aproximação com a prática de acupuntura e as dificuldades iniciais}

Eu resolvi fazer acupuntura por achar interessante, não tanto por curiosidade, mas por achar que era uma porta que poderia ajudar, e que essas medicinas poderiam caminhar de braços dados num 'casamento' harmonioso... Evidente que eu achei curioso também; imagine conseguir tratar com uma agulha, e, com isso, tive outra visão, eu pensei: 'Não é possível que exista isso... algo tão importante que aqui no Brasil e no Ocidente praticamente não existe e que só os orientais conheciam!'... Logo, eu comecei a me interessar, eu soube que os chineses, mas, sobretudo, os japoneses faziam acupuntura aqui em São Paulo. Nessa época, aqui no Brasil, a acupuntura era praticada mais dentro da própria colônia, entre os próprios imigrantes...

Quando eu comecei a estudar acupuntura e que eu vi o resultado, eu percebi que, realmente, a acupuntura era muito eficiente, de grande importância, e que poderia ser usada sem necessidade de rompimento com a medicina ocidental; desta forma, eu poderia fazer uma associação muito mais interessante... por exemplo, um indivíduo com pneumonia, se for tratado com antibiótico, ele melhora, mas, se for tratado com antibiótico e acupuntura, as respostas são muito melhores, a recuperação é muito mais rápida, melhor, com menos sofrimento e menos agressão até mesmo pelo próprio medicamento...

O meu interesse pela acupuntura vem desde o tempo em que eu era estudante; estava fazendo o terceiro ou o quarto ano médico, quando li um trabalho a respeito de acupuntura numa revista médica francesa, Presse Medicale, e, coincidentemente, alguns meses depois, li outro artigo na revista da Ciba, aquela empresa suíça, a Ciba Foundation. Achei muito interessante essa coincidência e, a partir de então, comecei a me interessar por essa prática milenar chinesa. Nesta época, eu sempre estava à procura de notícia, só que a maior parte era informação superficial...

De modo geral, não tinha muita coisa aqui no Brasil, no Rio Grande do Sul não tinha nada. Quando vim para São Paulo, eu tinha a esperança de ter contacto com a acupuntura, porque tem uma colônia oriental muito grande, mas não tive acesso. Eu imaginei que, em São Paulo, na Santa Casa de Misericórdia, eu teria mais acesso, afinal, eu tinha e tenho amigos, alunos e colegas nisseis. As colônias japonesas eram muito fechadas e, infelizmente, não tive acesso. Só muito adiante, já no fim da década de 1950, uma tia minha, que morava no Rio de Janeiro, descobriu que havia uma pessoa que ela pensava que era médico, mas, na realidade, não era médico, era fisioterapeuta, o Frederico Spaeth, que fazia acupuntura... Eu fui à sua procura e em contacto com o Frederico, ele disse: 'Eu ensino e atendo quem quiser, quem tiver interesse...', que é o contrário dos núcleos orientais daqui de São Paulo.

O Frederico resolveu fazer um curso de acupuntura geral aqui em São Paulo para quem tivesse interesse. Ele vinha uma vez por semana para São Paulo, passava quarta, quinta e sexta, e trabalhava no Rio de Janeiro sábado, domingo, segunda e terça; aos domingos, ele atendia mais os amigos, um ambiente mais familiar do que propriamente profissional. 


\section{Fundação da Associação Brasileira de Acupuntura}

Então, no final de 1958, o Frederico, junto com todo o grupo que tinha terminado esse primeiro curso de acupuntura, fundaram a Sociedade Brasileira de Acupuntura e Medicina Oriental. Em 1972, nós mudamos os estatutos e simplificamos o nome para Associação Brasileira de Acupuntura, porque, na realidade, nossa meta, nosso objetivo e nosso trabalho eram com acupuntura; as outras práticas da Medicina Chinesa, como, por exemplo, a fitoterapia, a gente não trabalhava...

A Associação Brasileira de Acupuntura, que fez cinquenta e poucos anos recentemente, continua oferecendo cursos de acupuntura. Expandimos e, atualmente, estamos presentes em grande parte dos estados do país, ministrando aquilo que começou com o Frederico Spaeth, no ano de 1958... A Associação Brasileira de Acupuntura tem desempenhado um papel extraordinário; de forma pioneira, nós difundimos a acupuntura dando cursos regulares aqui em São Paulo, no Rio de Janeiro, inclusive na Faculdade de Medicina e Cirurgia do Rio de Janeiro.

\section{O marco da década de 1970 na introdução da acupuntura no Ocidente}

O ano de 1972 foi muito importante, porque o presidente Richard Nixon foi à China, depois de uma aproximação prévia anterior... e lá aconteceu um episódio interessante, um dos membros da comitiva do Nixon, o jornalista James Reston, teve uma crise de apendicite na China e foi operado normalmente com anestesia, uma operação comum que se faz em qualquer parte do mundo. Os melhores cirurgiões chineses atenderam-no, afinal, fazia parte da comitiva do Nixon... No pós-operatório, ele estava com aquele mal- estar decorrente de uma cirurgia deste gênero, em que há distensão abdominal, retenção de gases e fezes, dificuldade de urinar e uma sensação muito ruim... Então, um dos membros da equipe que o operou perguntou se, antes de fazer a medicação ocidental correspondente, ele aceitaria se submeter a uma sessão de acupuntura, e ele respondeu afirmativamente; o resultado foi significativo e imediato, com grande alívio. Deambulando pelo hospital, James Reston viu o trabalho de acupuntura, o que a acupuntura fazia, qual era a visão dos pacientes e como eles eram tratados. Ao regressar aos Estados Unidos, ele publicou, no The New York Times, uma série de reportagens a respeito da viagem, sempre destacando a eficácia da acupuntura, o que ele tinha percebido nele mesmo, e o que havia visto na China. A partir do James Reston, os Estados Unidos começaram a entender, respeitar e aceitar a acupuntura, bem como mandar pessoas à China para ver e estudar...

As traduções dessas reportagens do James Reston no The New York Times foram publicadas aqui no Brasil em diversos jornais. Em São Paulo, a publicação foi no Estadão, e, no Rio de Janeiro, no jornal O Globo... Então, mudou a visão da acupuntura no mundo ocidental, inclusive no Brasil, dentro do princípio de que o que é bom para os Estados Unidos é bom para o Brasil. Se é bom para os Estados Unidos levar todos os nossos artistas, nossos intelectuais, é bom para o Brasil... então, leva!

Para mim, especificamente, foi muito importante esse ano porque um pouco antes, em 1969 ou 1970, eu fui processado pelo Conselho Regional de Medicina do Estado de São Paulo por fazer acupuntura como médico. Isso era considerado um crime, uma violência à ética médica. Portanto, como eu fazia acupuntura e era médico, eu fui processado e condenado, em primeira instância; depois, eu recorri ao Conselho Federal de Medicina, que, na época, ainda estava no Rio de Janeiro. Neste ínterim, o Nixon voltou aos Estados Unidos e houve, também, as publicações do James Reston no The New York Times; com isso, eu fui beneficiado na segunda instância e absolvido pelo Conselho Federal de Medicina.

Posteriormente, eu também fui processado pelo Conselho Regional de Medicina do Estado de São Paulo e do Estado do Mato Grosso, porque eu dava aula para não médicos. Quer dizer, fui processado porque tinha 'cachorro' e fui processado porque não tinha 'cachorro'; é mais ou menos isso que aconteceu comigo... O fato é que eu fui absolvido e continuo médico, praticando a minha atividade como acupunturista e lecionando, porque o maior objetivo era dar o exemplo.

Cabe ressaltar que a década de 1970 também teve um resquício da década 1960, em que houve uma mudança de concepções acerca do corpo, da qualidade de vida, sobretudo, em decorrência 
do movimento hippie, que se expandiu no mundo, teve até aquele grande encontro de música, Woodstock... O movimento hippie também ajudou significativamente na mudança dessa visão acerca da acupuntura.

\section{Seu grande mestre e amigo: Frederico Spaeth}

O Frederico Spaeth teve muito prestígio não só aqui no Brasil, mas no mundo todo, pelo fato de ter tido muitos clientes de nível social, econômico e político elevado, e eu, pelo fato de ser professor da Santa Casa e gozar de certas facilidades de convites, difundimos juntos a acupuntura com conferências, palestras, simpósios, seminários, workshops e cursos. Nós organizamos, ao longo desses anos, nove Congressos Nacionais de Acupuntura com participação de profissionais do mundo todo; nós chamamos nacionais, embora viesse gente de fora do país, não só como conferencistas, mas também como participantes, e gente interessada, sobretudo da América do Sul, da Argentina, do Uruguai, do Chile e da Venezuela... levamos também para fora do país a nossa contribuição, mostrando a qualidade da acupuntura feita aqui no Brasil.

Embora nós participássemos de um modo muito ativo, o Frederico foi, sem dúvida, o grande nome de tudo isso. A acupuntura brasileira teve uma respeitabilidade muito grande, chegando ao ponto de o Frederico ser eleito Presidente da Associação Internacional de Acupuntura (Paris, França)... Nós sempre estivemos presentes, mostrando a qualidade da acupuntura exercida no Brasil. Nós sempre desenvolvemos um trabalho de altíssimo nível, respeitado internacionalmente; o Frederico é honoris causa em muitos países do mundo, eu sou honoris causa mais no Sri Lanka, na Venezuela, no Uruguai...

\section{Início da dicotomia - médicos e não médicos}

No início, até o terceiro ou quarto congresso de acupuntura, havia, na Associação Brasileira de Acupuntura, uma grande presença de médicos. Depois, começou a haver certa convicção por parte de alguns médicos de que somente eles poderiam fazer acupuntura, e não concordamos. Quem deve fazer acupuntura é quem sabe, sendo médico ou não... mesmo porque, nos cursos de medicina aqui no Brasil, o que se ensina de acupuntura é nada, são poucas escolas que dão algumas noções de acupuntura. Então, infelizmente, houve essa separação e hoje temos, portanto, uma dicotomia muito evidente, médicos e não médicos lutando em campos diferentes...

\section{Inserção da acupuntura no serviço público da cidade de São Paulo}

Quando a Erundina foi prefeita, ela se mostrou extremamente preocupada com a saúde, ela instituiu, na Secretaria de Saúde do Município, atendimentos de acupuntura. Nesta época, em muitos postos, foram abertos serviços de acupuntura, e o Delvo Ferraz foi o coordenador geral dos postos de acupuntura. Posteriormente, quando o Maluf sucedeu a Erundina, ele estabeleceu que somente médico poderia praticar acupuntura; com isso, além da qualidade ir para o 'brejo', a maior parte dos atendimentos de acupuntura nos postos de saúde, criados durante o governo da Erundina, foi interrompida. A Erundina fez um trabalho muito interessante, mas havia muito preconceito, porque era mulher e nordestina, mas extremamente inteligente... este trabalho que ela fez, por meio da Secretaria de Saúde do Município, foi fantástico, mas, depois, o Maluf decidiu que somente médicos poderiam fazer. Esta foi a grande escolha que a população fez, em vez da Erundina, mulher, nordestina, honesta, inteligente, digna e competente, escolheu outro, que fez um trabalho muito destruidor no que diz respeito à acupuntura aqui no Município de São Paulo.

O Delvo (Ferraz) era coordenador, ele desempenhou e desempenha um papel importante na acupuntura, digamos assim, mais ligada à área oficial. Como a Associação Brasileira de Acupuntura é uma entidade privada, a gente tem muita coisa, mas a linha privada só oferece apoio e suporte para o desenvolvimento da acupuntura nas áreas públicas. A gente participa dessas lutas e trabalhos; o Wu Tou Kwang inclusive participou e participa, de maneira muito ativa, junto conosco, no que diz respeito à acupuntura para médicos e não médicos. 


\section{Os "engodos"}

É muito prejudicial para o país esse engodo de dizer que só médico deveria fazer acupuntura, que só médico é capaz e tem competência para tal... É comum algum cliente dizer: 'Doutor, eu fiz acupuntura, mas foi com médico'. Evidente que existem médicos competentes, porém dizer que a acupuntura deveria ser exclusividade dos médicos é uma agressão à população brasileira. Será trágico se, por ventura, a acupuntura ficar exclusiva aos médicos, porque esse perigo é real, como pode ser verificado na existência do Ato Médico.

O Ato Médico, tal qual foi aprovado na Câmara dos Deputados, liquida a acupuntura para não médico; é muito possível, não digo provável, que seja aprovado, porque o lobby médico é muito forte. O médico tem um prestígio que nenhuma outra profissão goza... existem médicos na política e médicos que influenciam na política. Na verdade, esse poderoso lobby, que fez a aprovação do Ato Médico, é que lança os engodos, as mentirinhas ou 'mentironas'. Eu sou médico, então, imagina eu falar isso, defender o não médico, para o Conselho Regional de Medicina, isso é uma coisa criminosa... Eu e o Wu fomos processados; eu tenho três processos já fechados, mas o Wu, como é mais político, foi até candidato a vereador, provavelmente tem ou teve muito mais...

\section{A fracassada experiência da França}

Um médico francês amigo meu, o Bernard Auteroche, respeitabilíssimo acupunturista e grande profissional, que infelizmente morreu há pouco tempo, me contou que, há cerca de vinte anos, a prática de acupuntura por não médicos foi proibida na França. Em consequência disso, a qualidade da acupuntura na França caiu vertiginosamente, e o número de acupunturistas diminuiu tão grandemente que boa parte da população, que tinha condições econômicas, ia se tratar nos países vizinhos... quem morava mais ao norte da França ia para Holanda, Bélgica ou Inglaterra, quem morava mais ao sul, ia para a Itália ou Espanha... Então, a acupuntura francesa sofreu enormemente, e isso redundou num prejuízo muito grande para a população, a situação foi tão dolorosa e trágica que, alguns anos depois, o Ministério da Saúde Francês voltou atrás. Hoje, na França, assim como na maioria dos países do mundo, médicos e não médicos podem praticar acupuntura; apenas em alguns poucos países há esta restrição, acredito que na Dinamarca, na Arábia Saudita, e em outro país que eu não me recordo. $\mathrm{Na}$ maioria dos países, a acupuntura é aberta para quem sabe, não para quem tem um diploma disso ou daquilo.

\section{A época da "perseguição séria" - Ditadura}

O Frederico foi preso pela polícia do Rio de Janeiro na época da perseguição séria, durante a ditadura; e o pai do Ricardo Maki, Sakae Maki, foi torturado pelo fato de fazer acupuntura, porque beneficiava e ajudava os outros...

$\mathrm{Na}$ época da ditadura, a perseguição era muito mais contra os que não eram médicos... eu fui perseguido e processado ainda na época da ditadura, no entanto era outra questão; a acupuntura era considerada, por muitos, como magia negra, vudu, charlatanismo, então, eu, como médico, não poderia fazer vudu... Em 1972, houve uma mudança desta visão após a publicação da história do James Reston e pelo resquício do movimento hippie, como já mencionei.

\section{Relações internacionais do Brasil}

Interessante, no início, a gente tinha uma relação muito grande com os países da América do Sul, sobretudo com a Argentina... todo ano, eles vinham para o Brasil para participar dos nossos encontros, dos nossos congressos, e a gente ia para lá, para participar dos encontros, ouvir tango e comer carne gostosa! O nosso grande contacto era, também, com a França, na realidade, por intermédio mais do Frederico, que foi o nosso mestre e o grande herói da acupuntura brasileira. $\mathrm{O}$ Frederico estudou com o Stiefvater, que foi aluno do George Soulié de Morant... 
O Soulié de Morant, diplomata e profundo conhecedor da tradição chinesa, foi quem trouxe a acupuntura para o Ocidente, especificamente para a França. Ele não era médico, quer dizer, não era médico aqui no Ocidente, mas, na China, ele recebeu o título de doutor em medicina oriental. O Soulié teve muitos alunos que, junto com o ele, complementaram seu próprio trabalho. Um desses alunos foi o Eric Stiefvater, aliás, a mulher dele também fez o curso com o Soulié, os alemães Ilse e Eric Stiefvater. O Frederico também era alemão, nascido em Luxemburgo, mas com nacionalidade alemã, e parte da família dele era francesa. Então, a nossa linha é francesa, e procuramos conservar o que há de mais profundo e puro da acupuntura tradicional chinesa.

O Soulié e o Frederico não eram médicos, coitados, penaram... o Frederico foi muito perseguido, intimidado com ameaças até meio veladas: 'Você não acha que é perigoso você fazer acupuntura?'.

\section{A lenda da origem da acupuntura - Atlântida}

Existem lendas que dizem que a acupuntura é muito anterior ao chinês; na verdade, a civilização da Atlântida teria sido o berço da acupuntura. A destruição da Atlântida favoreceu a expansão da acupuntura, porque, com o desaparecimento daquele núcleo, os sobreviventes se espalharam pelo mundo. Segundo essa lenda, quando a Atlântida foi destruída, os mais cultos, os mais importantes, os mais sabedores a respeito do assunto foram para a China, e os demais foram para as outras regiões do mundo, inclusive, para as Américas e para a África.

Então, aqui no Brasil, ainda hoje, algumas tribos indígenas fazem um arremedo de acupuntura... Um amigo meu, fisioterapeuta e acupunturista, trabalhava na Chapada dos Guimarães, e visitando o interior do Mato Grosso, sul do Pará, Rondônia, conseguiu anotar 104 pontos no corpo em que diferentes tribos faziam uma espécie de acupuntura. Uma aluna minha viu, na Ilha de Bananal, uma índia quebrar uma pedra aquecida ao sol e as espículas mais finas foram colocadas em outra índia com problema de saúde. O Frederico tinha uma cliente antropóloga casada com um índio, e que morou uma temporada numa aldeia, e ela confirmava a existência de uma espécie de acupuntura.

Em outras regiões do mundo também há resquícios históricos sobre a acupuntura; no Peru, com os incas; aqui no Brasil, eu vi, no Museu do Índio em Manaus, uma estante com estiletes de madeira e escrito embaixo: 'Estiletes usados por pajés para tratamento de saúde'. No México, com os astecas e os maias, existem também referências a uma espécie de acupuntura. Existe uma acupuntura egípcia; eu fiz o curso introdutório, usa-se somente uma agulha de prata, romba, que não penetra só toca. Na África do Sul, também tem uma forma de acupuntura rudimentar.

Enfim, não se sabe realmente se existiu essa tal Atlântida, mas, se tiver existido, explicaria a presença dessa forma primitiva de acupuntura a que eu estou me referindo. Bom, o fato é que a acupuntura tal qual nós conhecemos veio da China, embora uma amiga coreana diga que veio da Coreia e que, depois, foi para China... é brincadeira de uma acupunturista amiga minha, ela defende os patrícios dela. Ela explica que o tipo físico e a fisionomia de alguns personagens são mais parecidos com os coreanos do que realmente com os chineses... No entanto, o fato é que a acupuntura chinesa é realmente a primeira referência.

\section{Introdução da acupuntura no Brasil}

Eu li uma história em um panfleto publicado em Salvador mostrando que o ano de 1808 foi uma das primeiras referências da introdução da acupuntura chinesa no Brasil. Esta introdução se deu por meio da imigração de acupunturistas de Macau, trazidos por Dom João VI; naquela época, Macau era possessão portuguesa... Infelizmente, não sei onde foi que eu deixei essa publicação, porque eu viajei, mudei de casa, de cidade, passei cinco anos em Cuiabá... Dizem que três mudanças são iguais a um incêndio, e eu fiz cerca de quatro mudanças...

Em 1858, há referências de acupunturistas que vieram para São Paulo, japoneses que vieram para a região do Vale do Ribeira, e japoneses que foram para o Pará para o cultivo de pimenta do reino, na região de Tomé-Açu, que ainda hoje é o grande produtor de pimenta-do-reino aqui no Brasil... 
Contudo, esses japoneses que trouxeram a acupuntura não deram continuidade, não houve interesse de passar adiante...

Em 1908, chegou ao Brasil o navio japonês, o Kasato Maru, trazendo imigrantes e também acupunturistas; a partir daí, houve continuidade da acupuntura, porém restrita e limitada à colônia. Eu acredito que devia ser difícil praticá-la fora da colônia, até mesmo por questões de preconceito, provavelmente, eles se defendiam assim, se fechando...

E por fim, em 1958, foi fundada a Associação Brasileira de Acupuntura. Eu gosto de lembrar esses fatos, primeiro, porque esse lado é pouco conhecido; segundo, porque houve uma coincidência de cinquenta anos: 1808, a chegada de Dom João VI; 1858, a chegada desses imigrantes para Tomé-Açu; 1908, a chegada do Kasato Maru; 1958, a fundação da Associação Brasileira de Acupuntura.

\section{A luta pelos direitos da prática da acupuntura}

Nós corremos um risco muito sério, porque eu entendo que, se aqui no Brasil a acupuntura for restrita aos médicos, vai ser trágico para a população, uma tragédia em longo prazo. O povo não vai entender, nem sequer perceber - já não percebe hoje, por causa desse engodo, afinal de contas, a própria mídia é dominada por médicos. Então, a população, coitada, nem sabe disso, nem sabe que fazer acupuntura no decorrer da vida é bom para a saúde, nem sabe que, ao se fazer acupuntura em gestante, a criança nasce em melhores condições e a gestação correrá muito mais sossegada e tranquila... talvez os próprios médicos que fazem essa 'coisa' que eles chamam de acupuntura, que deveria se chamar 'agulhaterapia', nem saibam. Enfim, nós corremos esse risco. Esse ano de 2012 talvez não, porque é o ano das eleições municipais, ano de CPIs, então, toda a preocupação está voltada para isso; tem muito movimento, mas, quando acalmar, o lobby vem com tudo, com força total!

Há pouco foi publicado que somente os médicos poderiam praticar acupuntura, mas não colocaram que ganhou apenas uma liminar, esses são os engodos aos quais eu me refiro... é uma forma de usar a mídia a favor. Infelizmente, a mídia acata e transmite essas ideias; primeiro, a influência médica sobre ela é ampla; segundo, o número de médicos que fazem acupuntura e escrevem sobre acupuntura, como o caso daquele médico que aparece na Globo sempre, um dos maiores inimigos da acupuntura multiprofissional do país, o Drauzio Varella, é grande.

Hoje, eu defendo que todo médico deveria ter, pelo menos, alguma noção, não para fazer acupuntura, mas para entender que é útil e eficiente; e, desta forma, recomendar acupuntura ou dirigir aquele paciente para quem sabe. Essa minha forma de ver já me deu muita 'dor de cabeça'... continua dando algumas pelo fato de eu defender que não médico pratique acupuntura e achar criminoso e trágico se a acupuntura ficar restrita aos médicos. No mundo civilizado não é considerada exclusividade médica: nos Estados Unidos, na França, no Canadá, na Inglaterra, na Alemanha; por que é que o Brasil quer ser diferente dos outros? Por que os sábios brasileiros, os sábios médicos brasileiros, defendem esses argumentos tão falaciosos?

A acupuntura pode, realmente, levar à morte; há cerca de 15 anos, foi publicada, na Dinamarca, notícia sobre a morte de uma pessoa por acupuntura... Esse episódio foi uma fatalidade, o médico inseriu uma agulha no acuponto VC17, que corresponde a uma área em que, frequentemente, há uma malformação conhecida como Persistência do Forame Oval, em que não há o fechamento do esterno. O médico fez o tratamento na moça, e ela conversando bateu, a agulha penetrou e tocou na área de estimulação cardíaca...

Existe também o risco de pneumotórax, até hoje, a maioria foi causada por médicos; na realidade, grande parte dos acidentes por acupuntura foi causado por médicos... mas, infelizmente, não mencionam isso, assim como esquecem de dizer que a incidência de problemas decorrentes do uso de acupuntura é insignificante.

Eu pedi a uma cliente minha, que trabalha na Bireme, para fazer um levantamento dos acidentes que aconteceram em dez anos, de meados da década de 1980 a 1990, dos casos de infecção, 
contaminação e pneumotórax causados por acupuntura; o total levantado por ela foi de duzentos e tantos casos. O Colégio Médico de Acupuntura publicou essa informação mostrando o 'grande risco', porque, em dez anos, havia cerca de trezentos casos publicados... provavelmente, daria mais contando os que não foram publicados. Vamos supor que sejam seiscentos, em dez anos... isso significa, em média, sessenta casos por ano e cerca de cinco casos por mês no mundo todo. Quantos bilhões de inserções estão sendo realizados neste momento, lembrando que a China tem um bilhão e trezentos milhões de habitantes, a Índia quase a mesma coisa, o Japão tem mais de cem milhões de habitantes, e no resto do mundo? Quantos casos de infecção hospitalar estão acontecendo neste momento em Rondônia, São Paulo, Rio de Janeiro, Brasília, Porto Alegre, Florianópolis? Quantos casos de erros médicos estão acontecendo agora em Belo Horizonte, Porto Alegre, Florianópolis, Curitiba, Fortaleza, Manaus, Brasília, Cuiabá? Quer dizer, é um argumento falacioso, sórdido, mentiroso...

Quanto ao argumento dos médicos sobre a questão do diagnóstico, vale ressaltar que a acupuntura de qualidade tem seu diagnóstico próprio; o acupunturista não precisa tanto do diagnóstico ocidental, se tiver esse diagnóstico também, ótimo. Entretanto, não é essencial o diagnóstico ocidental, já que o acupunturista possui os métodos para fazer o seu próprio diagnóstico. Portanto, isso também é um argumento falacioso.

Outra questão interessante é que, normalmente, os brasileiros que fazem acupuntura só procuram este tratamento como último recurso... já procuraram médicos, têm um monte de exames e de diagnósticos, muitas vezes conflitantes; já foram em benzedeira, não deu certo, por fim, resolveram procurar acupuntura... Portanto, essa questão do diagnóstico é um argumento de quem não tem argumento. Então, eu e outros profissionais que conheço defendemos essa ideia com o risco até de perder o diploma... eu nunca fui ameaçado de nada, as ameaças foram somente sobre os coitados do Frederico e do Maki.

As décadas de 1960 e 1970 foram bem difíceis... se, por um lado, era a época dos hippies, por outro lado, era época de intensa perseguição da ditadura. O berço da acupuntura é a China e, se veio da China, era considerada comunista, e, se era comunista, precisava ser combatida... É com tristeza que eu digo que foi assim, esse aspecto político foi sério... Então, muitas vezes, os acupunturistas eram considerados comunistas; justamente porque a acupuntura veio da China, eles associavam uma coisa à outra... Portanto, grande parte da perseguição era dessa ordem.

\section{O preconceito}

Houve muito preconceito por parte dos meus colegas, eu fui vítima de muito preconceito e processado porque fazia acupuntura. Foi muito difícil, já paguei alguns pecados, não todos; muitos eu ainda não paguei, mas tenho a consciência de que procurei fazer o melhor, o mais justo, o mais certo... aquilo que as minhas convicções e meus ideais me apontaram como honesto, digno [...] e, posso dizer, como arma para ajudar os outros. Acredito que eu ajudei e ajudo, ensinei e ensino a ajudar; tem uma música que diz: 'enquanto houver força em meu peito... ', então eu digo: 'enquanto houver força em meu peito, eu ajudarei e ensinarei a ajudar'.

\section{Colaboradores}

Os autores participaram, igualmente, de todas as etapas de elaboração do artigo. 


\section{Referências}

1. Gallian DMC. 75x75: EPM/Unifesp, uma história, 75 vidas. São Paulo: Unifesp; 2008.

2. Meihy JCSB. Manual de história oral. São Paulo: Loyola; 2005.

3. Meihy JCSB, Holanda F. História oral: como fazer, como pensar. São Paulo: Contexto; 2007.

Palavras-chave: Acupuntura. História oral. Entrevista. Regulamentação de Organismos de Política.

Keywords: Acupuncture. Oral History. Interview. Regulations for Policy Organizations. Palabras clave: Acupuntura. Historia Oral. Entrevista. Reglamentación de Organismos de Política. 
